\title{
IMPLEMENTASI KINCIR ANGIN SAVONIUS 2 TINGKAT MENGGUNAKAN GENERATOR MAGNET PERMANEN
}

\author{
Jefri Lianda ${ }^{1}$, Hikmatul Amri ${ }^{2}$ \\ 1,2 Jurusan Teknik Elektro, Politeknik Negeri Bengkalis \\ Bengkalis 28711, email: jefri@polbeng.ac.id
}

\begin{abstract}
This paper focuses on improving the performance of a two-tiered windmill savonius to generate electricity through a permanent magnet generator. This study used an experimental method, taking into account the number and angle of the wind turbine Savonius two levels. The study was conducted at wind speed conditions of about $2.85 \mathrm{~m} / \mathrm{s}$ to $6.42 \mathrm{~m} / \mathrm{s}$. Dimensions of windshield savonius blades with a width of $45 \mathrm{~cm}$ and a height of $50 \mathrm{~cm}$. The wind turbine is installed with a height of 3.5 meters from the ground. This study uses a gearbox with a ratio of 1: 3.This study produces a maximum power of 95 watts. The average voltage generated 13.75 volts $A C$ to 19.52 volts $A C$. The energy supplied to the battery uses a battery charger control (BCR).
\end{abstract}

Keywords: savonius, permanent, gear box, BCR

\begin{abstract}
Abstrak
Makalah ini berfokus pada peningkatan kinerja kincir angin savonius dua tingkat untuk menghasilkan listrik melalui generator magnet permanen. Penelitian ini mengunakan metode eksperimen dengan memperhitungkan jumlah dan sudut turbin angin savonius dua tingkat. Penelitian ini dilaksanakan pada kondisi kecepatan angin sekitar 2,85 m/det sampai 6,42 $\mathrm{m} /$ det. Dimensi sudu kincir angin savonius dengan lebar $45 \mathrm{~cm}$ dan tinggi $50 \mathrm{~cm}$. Turbin angin dipasang dengan ketinggian 3,5 meter dari permukaan tanah. Penelitian ini mengunakan gear box dengan rasio 1:3. Penelitian ini menghasilkan daya maksimum sebesar 95 watt. Tegangan rata-rata yang dihasilkan 13,75 volt AC sampai 19,52 volt AC. Energi yang disalurkan ke baterai menggunakan battery charger control (BCR).
\end{abstract}

Kata Kunci : savonius, permanen, gear box, $B C R$

\section{PENDAHULUAN}

Kuantitas kebutuhan energi telah menjadi indikator standar kehidupan dan tingkat industrialisasi. Saat ini sekitar sembilan puluh persen energi dunia berasal dari penggunaan bahan bakar fosil, seperti: batubara, minyak bumi, gas alam, dan lain-lain. Manusia menggunakan bahan bakar fosil untuk memasok hampir semua kebutuhan energinya, seperti menyalakan kendaraan, menghasilkan listrik untuk penerangan. Di sisi lain, sumber energi dari energi fosil bumi terbatas. Pada saat bersamaan ada masalah dengan perubahan iklim akibat emisi karbon dioksida dan sulfur dioksida dari pembakaran bahan bakar fosil. Pemanfaatan energi terbarukan untuk sumber energi rendah karbon dan hemat biaya dapat menjadi tujuan penting kebijakan energi dalam kehidupan. Energi terbarukan adalah energi ramah iklim karena tidak adanya emisi yang merugikan lingkungan. Badan energi internasional tersebut menyatakan bahwa hanya sebagian kecil energi yang berasal dari pembangkit listrik tenaga nuklir dan tenaga air, dan bagian yang sangat kecil dari sumber energi terbarukan seperti gelombang surya, angin, biomassa, panas bumi dan pasang surut [1].

Kincir angin mengubah energi kinetik menjadi energi listrik. Kincir angin dikelompokkan menjadi dua kelas yaitu Turbin Angin Sumbu Vertikal (VAWT) dan Turbin Angin Sumbu Horizontal (HAWT). Turbin Angin Sumbu Horizontal yang sebelumnya menjadi alat yang paling populer untuk pembangkit listrik karena efisiensinya lebih tinggi karena kecepatan rotasi yang tinggi. Tapi HAWT memerlukan struktur yang lebih rumit dari pada VAWT dan hanya layak dilakukan ke daerah di mana angin permanen dengan kecepatan tinggi tersedia [2].

Turbin angin Savonius, ditemukan pada tahun 1929, memiliki konfigurasi sederhana dibandingkan dengan jenis kincir angin lainnya. Karena itu, biaya yang terlibat dalam pengembangannya bisa lebih rendah. Selain itu, turbin angin Savonius menghasilkan suara yang lebih rendah dan memiliki kinerja yang baik dengan kecepatan angin sedikit [3].

Implementasi Kincir Angin Savonius 2 Tingkat Menggunakan Generator Magnet Permanen (Jefri Lianda) 
Sigurd J. Savonius dari Finlandia pada tahun 1931 menemukan turbin angin tipe Savonius, yang dikenal dengan S-rotor. Turbin angin Savonius telah mendapatkan hak paten. Turbin terdiri dari dua bagian silinder dan kemudian memutar dua permukaan semi-silinder ke samping sepanjang bidang potongan seperti huruf S. Dua permukaan setengah lingkaran, disebut sudu, terhubung pada sumbu vertikal yang tegak lurus terhadap arah angin dengan celah pada sumbu antara sudu. Turbin Savonius berfungsi seperti anemometer cangkir atau perangkat berbasis drag. Rasio kecepatan suduterhadap kecepatan angin kurang dari satu kesatuan ini karena suduyang kembali di sisi angin tidak akan pernah bisa berputar lebih cepat dari pada angin. Savonius meneliti kinerja tiga puluh model S-rotor yang berbeda di terowongan angin dan udara terbuka [4].

Jumlah peneliti yang mempelajari berbagai model turbin angin Savonius sangat banyak. Kendati demikian, untuk mengetahui lebih detail parameter desain pasti menunjukkan bahwa tidak ada produk analisis yang bisa memberi pengetahuan tentang pengaruh sudut heliks pada kinerja VAWT. Studi sebelumnya mendorong peneliti untuk mengembangkan dan mengoptimalkan turbin angin savonius dengan sudut heliks yang berbeda dengan cara eksperimen dan perhitungan numerik. Oleh karena itu, tujuan utama dari penelitian ini adalah untuk mengetahui variasi koefisien daya dan pola aliran turbin angin pada sudut heliks yang berbeda berdasarkan luas proyeksi konstan, yaitu luas rotor angin yang benar-benar menerima angin [3]. Generator harus dihubungkan ke poros turbin sehingga dapat mengubah energi mekanik dari turbin menjadi energi listrik [5].

\section{LANDASAN TEORI}

Sebuah turbin angin adalah perangkat yang mengubah energi kinetik dari angin menjadi tenaga listrik. Vertikal Axis Wind Turbin (VAWT) adalah salah satu jenis turbin angin mana poros rotor utama diatur secara vertikal dan dapat menangkap angin dari segala arah [6]. Energi angin dapat dikonversi atau ditransfer ke dalam bentuk energi lain seperti listrik atau mekanik dengan menggunakan kincir atau turbin angin. Oleh karena itu, kincir atau turbin angin sering disebut sebagai Sistem Konversi Energi Angin (SKEA). Turbin Savonius adalah turbin yang mudah digunakan dan beroperasi karena perbedaan daya yang diperoleh di sisi baling-baling. Area sudukincir angin mendapat energi angin sehingga sudubergerak di sekitar sumbu vertikal tengah. Gambar 1 memperlihatkan kontruksi kincir angin savonius dengan 2 bilah.

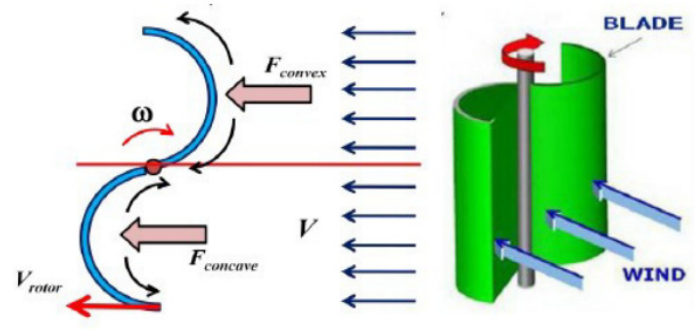

Gambar 1: Desain turbin angin savonius [6]

Kinerja turbin angin savonius dapat dilambangkan dalam bentuk koefisien torsi (Ct) dan koefisien daya $(\mathrm{Cp})$ dibandingkan dengan rasio kecepatan tip atau TSR $(\lambda)$. Rasio kecepatan tip adalah variabel yang sesuai dengan kecepatan angin dan diameter rotor. Sebagai perbandingan antara kecepatan ujung pisau dan kecepatan angin melalui mata pisau, TSR dapat dirumuskan sebagai [7].

$$
\operatorname{TSR}=\lambda=\frac{\mathrm{V}_{\text {rotor }}}{\mathrm{V}}=\frac{\omega . \mathrm{d}}{\mathrm{V}}
$$

Dengan rotor $\mathrm{V}$ adalah kecepatan tip atau kecepatan periferal rotor $(\mathrm{m} / \mathrm{s}) ; \Omega$ adalah kecepatan sudut rotor (1 / s); D adalah diameter silinder rotor, $(\mathrm{m})$, dan $\mathrm{V}$ adalah kecepatan angin $(\mathrm{m} / \mathrm{s})$.

Koefisien torsi atau Ct didefinisikan sebagai rasio antara torsi aktual yang dikembangkan oleh rotor (T) dan torsi teoritis yang tersedia dalam angin (Tw) sebagai

$$
\mathrm{C}_{\mathrm{t}}=\frac{\mathrm{T}}{\mathrm{T}_{\mathrm{w}}}=\frac{4 \mathrm{~T}}{\rho \mathrm{A}_{\mathrm{s}} \mathrm{dV}^{2}}
$$


dengan $\rho$ adalah densitas udara $(=1,225 \mathrm{~kg} / \mathrm{m} 3)$; T adalah torsi $(\mathrm{Nm})$, dan As adalah lebar dari sudu atau hasil perkalian antara diameter rotor dan tinggi ( $\mathrm{m} 2)$.

Koefisien kekuatan turbin angin (Cp) adalah perbandingan antara daya maksimum yang diperoleh dari angin $(\mathrm{Pt})$ dan daya total yang siap dari angin $(\mathrm{Pa})$ sebagai

$$
\mathrm{C}_{\mathrm{p}}=\frac{\mathrm{P}_{\mathrm{t}}}{\mathrm{P}_{\mathrm{a}}}=\frac{\mathrm{P}_{\mathrm{t}}}{\frac{1}{2} \rho \mathrm{A}_{\mathrm{s}} \mathrm{dV}^{3}}
$$

Dengan daya maksimal turbin angin dihitung sebagai

$$
\mathrm{Pt}=\mathrm{T} \omega \text { (watt) }
$$

Sambungan antara koefisien daya $\mathrm{Cp}$ dan rasio kecepatan tip TSR atau $\lambda$ sebagai hasil kebersamaan kinerja turbin angin ditunjukkan pada Gambar 2 [8]. Kurva menunjukkan bahwa satu putaran turbin angin memiliki kebersamaan kecil dan bentuk kurva $\mathrm{Cp}$ yang relatif datar yang disebabkan oleh kekuatan tarik yang lebih besar. Tiga suduturbin angin memberikan kebersamaan maksimal dengan maksimal $\mathrm{Cp}$ dan hasilnya menghasilkan lebih banyak energi.

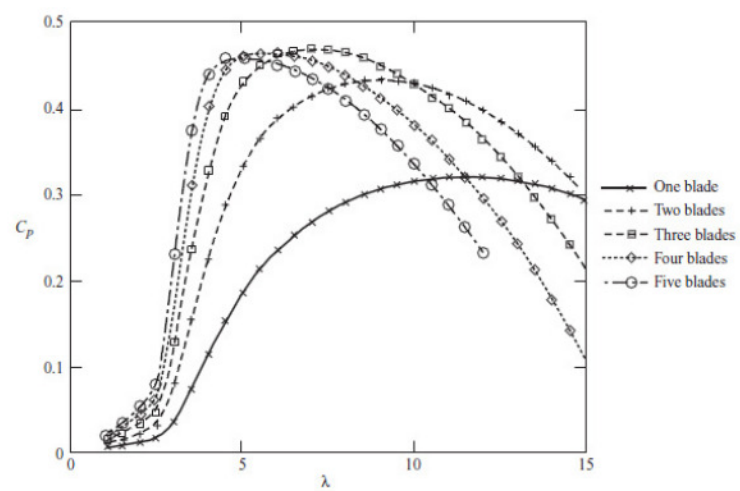

Gambar 2: Kurva koefisien daya $\mathrm{Cp}$ dan rasio kecepatan tip $\lambda$ turbin angin

Turbin angin sumbu vertikal (VAWT) dapat dioperasikan pada kecepatan angin rendah mulai dari 2 sampai 8 meter per detik. Keuntungan utama turbin angin sumbu vertikal (VAWT) jika dibandingankan dengan turbin angin sumbu horisontal (HAWT) adalah kemampuan untuk mendapatkan angin dari segala arah. sehingga sistem VAWT tidak diperlukan untuk mengubah arah rotor angin. Selain itu, tingkat kebisingan yang dihasilkan selama rotasi sangat sesuai untuk pemasangan di lingkungan perumahan dan perkotaan. Desain kincir angin yang sesuai dengan kondisi kecepatan angin rendah, maka turbin dapat berfungsi secara efisien dan memaksimalkan daya yang dihasilkan oleh turbin [9].

Penelitian Pengaruh Jumlah Sudu Terhadap Unjuk Kerja Turbin Angin Savonius. Menggunakan metode penelitian eksperimental dengan variasi jumlah sudu : 2, 3, dan 4 buah dengan variabel bebas kecepatan angin pada wind tunnel dari kecepatan $3 \mathrm{~m} / \mathrm{s}$ sampai $7 \mathrm{~m} / \mathrm{s}$. Didapatkan hasil analisis bahwa turbin angin dengan jumlah sudu 3 buah memiliki unjuk kerja yang tinggi dibandingkan dengan jumlah sudu yang lain[10].

\section{HASIL DAN PEMBAHASAN}

Model turbin angin Savonius dua tingkat diimplementasikan pada turbin angin kecepatan rendah seperti ditunjukkan pada Gambar 3. Turbin angin ini terdiri dari enam sudu yang disusun secara bertingkat yakni masing-masing tingkat sebanyak tiga sudu. Penelitian ini menggunakan generator magnet permanen dengan daya maksimal 300 watt. Kincir angin ini juga dilengkapi dengan battery charger control (bcr) dengan masukan tegangan tiga fasa dan arus pengisian maksimal 10 amper. Untuk memaksimalkan energi yang dihasilkan oleh generator magnet permanen maka peneliti menggunakan gear box. Gear box ini dapat meningkatkan putaran generator magnet permanen. 


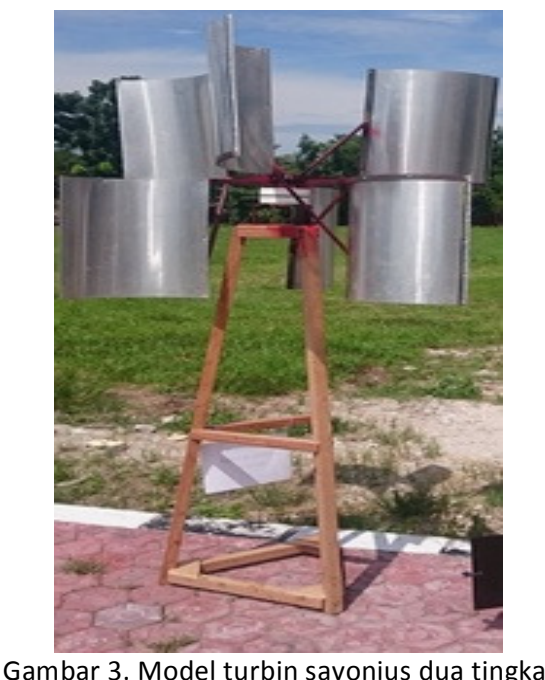

Pengujian kinerja kincir angin savonius dua tingkat dilaksanakan di pantai Selat Baru Bengkalis. Pengujian data dimulai pukul 09.00 GMT. Kecepatan angin rata-rata pada saat pengujian sekitar 2,85 m / s hingga 6,42 m / s. Tegangan yang dihasilkan oleh generator magnet permanen kira-kira 13,75 volt AC sampai 19,52 volt AC. Data pengujian berupa tegangan keluaran generator magnet permanen dan kecepatan angin dapat diliahat pada Gambar 4.

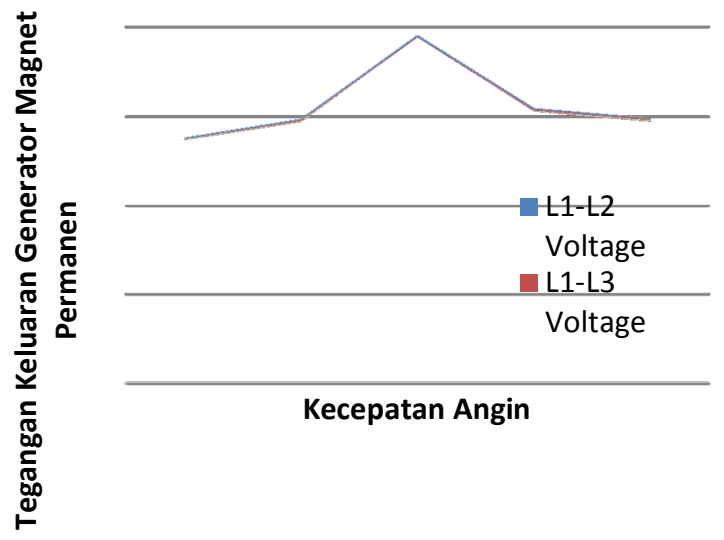

Gambar 4: Hubungan antara kecepatan angin dengan tegangan keluaran generator magnet permanen

Gambar 4 menjelaskan hubungan antara tegangan keluaran generator magnet permanen dengan kecepatan angin. Secara umum tegangan antar fasa keluaran dari generator magnet permanen seimbang. Turbin angin savonius dua tingkat menghasilkan tegangan antar fasa sekitar 13,8 volt AC pada kecepatan angin $2,8 \mathrm{~m} / \mathrm{s}$ dan 14,85 volt AC pada kecepatan angin 4,3 m/s. Tegangan maksimal yang dihasilkan pada penelitian ini sebesar 19,52 volt AC. Tegangan 19,52 volt AC diperoleh pada kecepatan angin sekitar 6,42 m/s. Singkatnya gambar 4 memperlihatkan bahwa tegangan keluaran yang dihasilkan oleh generator magnet permanen dipengaruhi oleh kecepatan angin. Semakin tinggi kecepatan angin maka tegangan keluaran generator magnet permanen semakin besar.

Tabel 1 memperlihatkan tegangan keluaran dan arus keluaran dari battery charger control (BCR). Secara umum tegangan masukan BCR berupa tegangan tiga fasa dan tegangan keluaran dari BCR berupa tegangan DC. Tegangan masukan BCR sebesar 13,80 VAC menghasilkan tegangan keluaran sebesar 12,95 VDC. Tegangan keluaran BCR 12,95 VDC telah dapat mengecas baterai 12 volt DC dengan arus pengisian sebesar 
6,41 amper dan daya yang dihasilkan sebesar 83 watt. Daya maksimal yang dihasilkan oleh kincir angin savonius dua tingkat sebesar 103 watt. Daya ini diperoleh pada kondisi tegangan keluaran BCR sebesar 14,5 VDC dan arus keluaran sebesar 7,13 amper. Tabel 1 memberi informasi mengenai daya yang bisa disimpan di baterai 12 VDC. Daya rata-rata yang diperoleh sebesar 95 watt.

Tabel 1 : Pengujian battery charger control (BCR)

\begin{tabular}{|c|c|c|c|c|c|}
\hline \multirow{2}{*}{ No } & \multicolumn{3}{|c|}{$\begin{array}{l}\text { Tegangan Masukan } \\
\text { (VAC) }\end{array}$} & \multirow{2}{*}{$\begin{array}{c}\text { Tegangan } \\
\text { Keluaran } \\
\text { (DCV) }\end{array}$} & \multirow{2}{*}{$\begin{array}{l}\text { Arus } \\
\text { Keluaran } \\
\text { (DCA) }\end{array}$} \\
\hline & $\begin{array}{l}\mathrm{L} 1- \\
\mathrm{L} 2\end{array}$ & $\begin{array}{c}\mathrm{L} 1- \\
\mathrm{L} 3\end{array}$ & $\begin{array}{c}\mathrm{L} 2- \\
\mathrm{L} 3\end{array}$ & & \\
\hline 1 & 13,80 & 13,78 & 13,75 & 12,95 & 6,41 \\
\hline 2 & 14,85 & 14,80 & 14,75 & 13,98 & 6,76 \\
\hline 3 & 19,52 & 19,48 & 19,49 & 14,50 & 7,13 \\
\hline 4 & 15,45 & 15,38 & 15,35 & 14,25 & 6,94 \\
\hline 5 & 14,90 & 14,84 & 14,78 & 13,95 & 6,74 \\
\hline
\end{tabular}

\section{SIMPULAN}

Penelitian ini menghasilkan kincir angin savonius dua tingkat. Kincir angin memutarkan generator magnet permanen listrik permanen. Kecepatan putaran generator dapat dinaikkan dengan menggunakan gear box dengan rasio 1:3. Energi listrik yang dihasilkan oleh kincir angin savonius dua tingkat telah dapat disimpan di dalam baterai 12 VDC dengan daya rata-rata 95 watt.

\section{DAFTAR PUSTAKA}

[1] W. Frederikus, S. Andy, and S. Hadi, "An experimental study on the performance of savonius wind turbines related with the number of blades", 2nd International Conference on Sustainable Energy Engineering and Application, ICSEEA, Energy Procedia, vol. 68, 2015, pp. 297-304.

[2] A. Wasi-Udin, Z. Junayed-Hasan, R. Azimur, and M. Mamun," Numerical study of two and three bladed savonius wind turbine," IEEE International Conference on Green Energy and Technology, vol. 2nd, 2014, pp. $36-40$

[3] L. Jae-Hoon, L Young-Tae, and L. Hee-Chang, "Effect of twist anngle on performance of savonius wind turbine," Renewble Energy, vol. 89, pp. 231-244, 2016.

[4] Savonius SJ, The wing rotor in theory and practice. Savonius : 1928

[5] A.A. Safe, S. Kashem, M. Moniruzzaman, "Design, fabrication and analysis of twisted blade vertical axis wind turbine(VAWT) and a simple alternator for VAWT," IEEE Strategic Technology (IFOST), vol. 9, pp. 304-308, 2014.

[6] R. Renato, R. Roberto, M. Sergio, and V. Daniele, "Experimental study on a sovonius wind rotor for street lighting system," Applied Energy, vol. 161, pp. 143-152, 2016.

[7] AR. Jha, Wind Turbine Technology, New York: CRC Press, Taylor \& Francis Group, 2011.

[8] A. Chauvin, and D. Benghrib, Drag and lift coefficients evolution of a sovonius rotor exp. fluids, 1989.

[9] A. Aziz, A. Mohamad, and F. Hamidon, "A simulation study on airfoils using VAWT design for low speed application" IEEE Engineering Technology and Technopreneuship (ICE2T), Kuala Lumpur, vol. 4th 2014, pp. 105-109.

[10] Syamsul BW, Taufan, Hamdani, "Unjuk kerja turbin angin savonius dua tingkat empat sudu lengkung L", Seminar Nasional Teknik Mesin Universitas Trisakti (SNTMUT), 2014, 1-6. 